\title{
Perovskite-Quantum Dots Interface: Deciphering its Ultrafast Charge Carrier Dynamics
}

Pavel Galar ${ }^{1}$, Piotr Piatkowski ${ }^{1 \dagger}$, Thi Tuyen $\mathrm{Ngo}^{2}$, Mario Gutiérrez ${ }^{1}$, Iván Mora-Seró ${ }^{2 *}$ and Abderrazzak Douhal $^{1 *}$

${ }^{1}$ Departamento de Química Física, Facultad de Ciencias Ambientales y Bioquímica, y INAMOL, Avenida Carlos III, S/N, Universidad de Castilla-La Mancha (UCLM), 45071, Toledo, Spain.

${ }^{2}$ Institute of Advanced Materials, Av. de Vicent Sos Baynat, S/N, Universitat Jaume I, 12006, Castelló de la Plana, Spain.

*Corresponding authors: abderrazzak.douhal@uclm.es; sero@uji.es

${ }^{\dagger}$ Current address: Faculty of Chemistry, University of Warsaw, Pasteura 1, 02-093, Warsaw, Poland.

\begin{abstract}
Understanding electron and hole $(\mathrm{e}, \mathrm{h})$ transport at semiconductor interfaces is paramount to developing efficient optoelectronic devices. Halide perovskite/semiconductor quantum dots (QDs) have emerged as smart hybrid systems with a huge potential for light emission and energy conversion. However, the dynamics of generated e-h pairs are not fully understood. Ultrafast UV-VIS transient absorption and $\mathrm{THz}$ spectroscopies have enabled us to unravel the processes of the e-h recombination within a hybrid film of methylammonium lead triiodide $\left(\mathrm{MAPbI}_{3}\right)$ interacting with different amount of $\mathrm{PbS} / \mathrm{CdS}$ core/shell QDs. To accurately analyse the complex behaviour, we applied a new model for e-h events in this hybrid material. The results obtained with sample having a high concentration of QDs (7.3 mass percentage) indicate: $(i)$ a large population (92\%) of the photogenerated charge carriers are affected by QDs presence. The main part of these carriers ( $85 \%$ of the total) in perovskite domain diffuse towards QDs, where they transfer to the interface (electrons) and QD's valence bands (holes) with rate constants of $1.2 \times 10^{10} \mathrm{~s}^{-1}$ and $4.6 \times 10^{10} \mathrm{~s}^{-1}$, respectively. $7 \%$ of these affected charged entities
\end{abstract}


are excitons in the perovskite domain in close vicinity of the interface, and show a recombination rate constant of $3.7 \times 10^{10} \mathrm{~s}^{-1}$. (ii) The carriers not affected by QDs presence (8\%) recombine through known perovskite deactivation channels. Lowering the QDs mass percentage to 0.24 causes a decrease of electron and hole effective transfer rate constants, and disappearance of excitons. These results provide clues to improve the performance of perovskite/QD based devices.

Keywords: Perovskite; quantum dots; LEDs; Lighting; hybrid nanostructures; electron and hole dynamics.

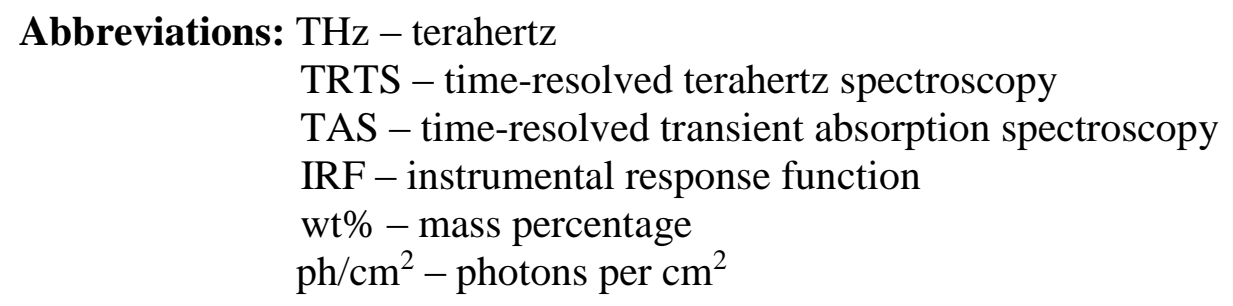

\section{Introduction}

Over the past few years semiconductor colloidal quantum dots (QDs) and trihalide perovskites have been intensively studied [1-6]. The outstanding properties of semiconductor QDs, such as the tunability of the optical band gap across a wide range of energies and their high light absorption coefficient, make them attractive for heterojunction solar cells, lightemitting diodes (LEDs) and lasers [1-3, 7, 8]. Halide perovskites solar cells have achieved photoconversion efficiencies (PCE) higher than 22\% [9], and the performance of LEDs, photodetectors and lasers based on halide perovskites has improved continuously over the past few years [4, 10-17]. Beyond this scenario, a combination of materials with different natures could provide interesting synergistic interactions that would produce advanced configurations enhancing the performance of related optoelectronic devices. In this sense, the composites of perovskite and semiconductor QDs have shown strong potential in lighting and photovoltaic 
conversion [18-27]. QDs solar cells showed a significant but lower efficiency than that of other photovoltaic devices due to the low charge carrier mobilities and high surface trap density [2831]. By combining the efficient charge generation in QDs and the e-h high mobility in the perovskite, efficient colloidal QDs solar cells were fabricated [20-22].

The use of perovskite as a passivating agent for QDs surfaces led to a material that can act as a highly conductive matrix to increase the power conversion efficiency (PCE) of photovoltaic devices based on lead trihalides $[19,27]$, as well as the efficiency of IR LEDs [25] and photodetectors [26]. Perovskite and small core/shell QDs have been combined to prepare voltage tunable LEDs that exhibit exciplex emission, which could be used for developing advanced solar cell configurations, such as intermediate band gap ones [23]. In addition to that $\mathrm{PbS}$ QDs have been used as seeds to grow perovskite solar cells with larger grain sizes, significantly increasing the performance of the solar cells $[19,24]$. These results clearly show the enormous potential of combining perovskite and QD materials to develop highly efficient advanced optoelectronic devices. However, detailed studies of the photoinduced processes that occur in these composites are lacking. Understanding the ultrafast events in perovskite/QDs interfaces, such as charge carrier transfer and recombination dynamics, is paramount to improving the overall efficiency of optoelectronic devices based on these materials. However, the real-time observation of the interfacial processes remains unexplored.

Herein, we report on studies of thin polycrystalline films of methylammonium lead triiodide $\left(\mathrm{MAPbI}_{3}\right)$ matrix embedded with different concentrations of $\mathrm{PbS} / \mathrm{CdS}$ (core/shell) QDs, using ultrafast time-resolved transient visible-NIR absorption and terahertz (THz) spectroscopies (TAS and TRTS, respectively). By photogenerating charge carriers over the band gap of $\mathrm{MAPbI}_{3}(\sim 1.55 \mathrm{eV})$ in the $\mathrm{MAPbI}_{3} / \mathrm{QDs}$ hybrid material, we observed fast and efficient charge carrier deactivation due to their transfer to QDs. The initial $(<1 \mathrm{ps})$ population and mobilities of electrons and holes in the perovskite domain are not affected by the presence 
of QDs. To accurately elucidate the complex electrons and hole events within the material, we propose a new kinetic model. We found that: (i) the majority ( $90 \%)$ of photoexcited electrons and holes diffuse towards QDs and is afterwards transferred to the interface and QDs, respectively, (ii) few percent of them fast recombine as excitons in the close vicinity of the interface, and (iii) a small part of the photoexcited charges is not affected by the presence of QDs, and therefore follows the typical perovskite deactivation channels. Lowering the QDs concentration increases the carrier diffusion time, and thus slows down their effective transfer to the interface and QDs, and decreases the concentration of excitons. These results show high collection efficiency of electrons and holes by these QDs in this hybrid material, and the relevance of $\mathrm{MAPbI}_{3} / \mathrm{QDs}$ interface states in charge carrier transition/trapping processes. We propose that further optimization of perovskite/QD system requires a reduction of the interface traps. Of not less importance, the proposed kinetic model can be used to characterize the electron-hole events in other complex hybrid structures.

\section{Materials and Methods}

\subsection{PbS/CdS core-shell QD synthesis}

Core/shell quantum dots (QDs) were synthesized according to a previously reported procedure $[24,32]$. Briefly, a mixture of $0.9 \mathrm{~g}(4 \mathrm{mmol})$ of $\mathrm{PbO}, 2.7 \mathrm{~g}(9.6 \mathrm{mmol})$ of oleic acid $(\mathrm{OA})$ and $36 \mathrm{ml}$ of 1-octadecene (ODE) in a three-necked round-bottom flask was heated to $150^{\circ} \mathrm{C}$ under $\mathrm{N}_{2}$ to form $\mathrm{Pb}$-oleate moieties. The solution was degassed for 30 min under vacuum, then opened to $\mathrm{N}_{2}$, and $3 \mathrm{ml}(6.7 \mathrm{mmol})$ of trioctylphosphine $(90 \%)$ was injected. A mixture of $0.42 \mathrm{ml}(2 \mathrm{mmol})$ of hexamethyldisilathiane (HMDS) and $4 \mathrm{ml}$ of ODE was quickly injected to the flask when the temperature dropped to $110^{\circ} \mathrm{C}$. The solution was left to cool to room temperature. The reaction product was cleaned three times with ethanol/acetone $(1: 1, \mathrm{v} / \mathrm{v})$, centrifuged (3000 rpm for $10 \mathrm{~min})$ and dispersed in toluene $(100 \mathrm{mg} / \mathrm{ml})$. 
For the growth of the CdS shell, a flask containing $0.34 \mathrm{~g}(2.6 \mathrm{mmol})$ of $\mathrm{CdO}, 1.85 \mathrm{~g}$ ( $6.5 \mathrm{mmol}$ ) of $\mathrm{OA}$ and $40 \mathrm{ml}$ of $\mathrm{ODE}$ was heated to $220^{\circ} \mathrm{C}$ in air to dissolve $\mathrm{CdO}$, cooled to $150^{\circ} \mathrm{C}$ and then degassed for 1 hour under vacuum. After that, the temperature was reduced to $70^{\circ} \mathrm{C} .5 \mathrm{ml}$ of the as-prepared $\mathrm{PbS}$ QD suspension $(100 \mathrm{mg} / \mathrm{ml}$ in toluene $)$ was rapidly injected to the flask. The reaction was kept at $70^{\circ} \mathrm{C}$ for 5 min then stopped by adding the non-solvent mixture (ethanol/acetone, 1:1, v/v). The product was washed following the same washing steps used for $\mathrm{PbS}$ nanocrystals and dispersed in octane for the ligand exchange. After this process, $\mathrm{PbS} / \mathrm{CdS}$ QDs $3 \mathrm{~nm}$ in size were prepared.

\subsection{Ligand exchange and perovskite, perovskite/QDs solution preparation}

$1.5 \mathrm{ml}(10 \mathrm{mg} / \mathrm{ml})$ of $\mathrm{PbS} / \mathrm{CdS}$ core-shell QDs in octane was mixed with $0.5 \mathrm{ml}$ of dimethylformamide (DMF) containing $58.3 \mathrm{mg}$ of $\mathrm{PbI}_{2}$ and $25 \mathrm{mg}$ of methylammonium iodide (MAI). The as-mixed solution separated into 2 phases: at the top, QDs in octane (brown) and $\left(\mathrm{PbI}_{2}+\mathrm{MAI}\right)$ in DMF at the bottom (yellow). After stirring for $30 \mathrm{~min}$, the QDs transferred from the top octane phase to the bottom DMF phase, resulting in a color change: transparent at the top and dark at the bottom. The octane solution was removed and the QD solution was washed three more times using the same solution to remove the organic residue. Subsequently, the QDs were precipitated adding toluene. After removing all the liquids, the QDs were dried under vacuum and dispersed in perovskite solution $(0.4 \mathrm{M})$ to form a $\mathrm{MAPbI}_{3} / \mathrm{QDs}$ solution. The amount of $C_{\mathrm{QDs}}$ was varied from 2 to $200 \mathrm{mg} / \mathrm{ml}$. The $0.4 \mathrm{M} \mathrm{MAPbI}_{3}$ reference solution (without QDs) was prepared by dissolving $0.438 \mathrm{mmol}$ of $\mathrm{PbI}_{2}$ and $0.438 \mathrm{mmol}$ of MAI in a mixture of $1 \mathrm{ml}$ of DMF and $95 \mu \mathrm{l}$ of dimethyl sulfoxide (DMSO). Further details have been published in the relevant reference [24]. 


\subsection{Perovskite and perovskite/QDs film preparation}

Glass substrates were cleaned with soap, sonicated in distilled water, ethanol and isopropanol for $15 \mathrm{~min}$ and then treated with an $\mathrm{UV}-\mathrm{O}_{3}$ lamp for $15 \mathrm{~min} . \mathrm{MAPbI}_{3}$ or $\mathrm{MAPbI}_{3} / \mathrm{QD}$ films were spin coated at $9000 \mathrm{rpm}$ from $50 \mu \mathrm{l}$ of $\mathrm{MAPbI}_{3}$ or $\mathrm{MAPbI}_{3} / \mathrm{QD}$ solution, respectively. Diethyl ether was poured on a film after the spin coater was running for $4 \mathrm{sec}$. The films were annealed for $1 \mathrm{~min}$ at $65^{\circ} \mathrm{C}$ then for $2 \mathrm{~min}$ at $100^{\circ} \mathrm{C}$. The deposition was carried out inside a glovebox filled with $\mathrm{N}_{2}$.

\subsection{SEM and XRD measurement}

The morphology and structural properties of the films were analyzed using a field emission scanning electron microscope (JSM7001F, JEOL) and a Bruker AXS D4 X-ray diffractometer using $\mathrm{Cu} \mathrm{K} \alpha$ radiation.

\subsection{UV-VIS-NIR absorption spectroscopy}

The UV-VIS-NIR absorption spectra of the $\mathrm{MAPbI}_{3}, \mathrm{MAPbI}_{3} / \mathrm{QDs}$ and QDs were measured using a standard spectrophotometer (JASCO V-670). To eliminate the contribution of the scattered light, we carried out diffuse reflectance measurements using a $60-\mathrm{mm}$ integration sphere (ISN-723).

\subsection{Femtosecond transient absorption spectroscopy}

The used femtosecond (fs) transient UV-VIS-IR absorption setup has been described elsewhere [33]. Briefly, it consists of a Ti:sapphire oscillator (TISSA 50, CDP Systems) pumped by a $5 \mathrm{~W}$ diode-laser (Verdi 5, Coherent). The oscillator output pulses (30 fs, $480 \mathrm{~mW}$ at $86 \mathrm{MHz}$ ) centered at $800 \mathrm{~nm}$ were guided to a regenerative amplifier (Legend-USP, Coherent) and used as a seeding signal. The amplified fundamental beam (50 fs, $1 \mathrm{~W}$ at $1 \mathrm{kHz})$ 
was then directed through an optical parametric amplifier (OPA, CDP Systems) for wavelength conversion and an additional 1-mm BBO crystal for frequency doubling to obtain 400, 600, 700 and $740 \mathrm{~nm}$ pulses. The pump intensities ranged from $\sim 40$ to $250 \mu \mathrm{W}$. The transient absorption measurements were performed in the spectral ranges of $450-780 \mathrm{~nm}$. All the spectra analyzed in the visible-NIR region were corrected for the chirp of the white light continuum. To avoid sample degradation, the samples were moved during the measurement using the XY translational stage. The measured instrument response function (IRF) of the system was $\sim 70$ fs. All the experiments were performed at $293 \mathrm{~K}$ [34].

\subsection{Sub-picosecond time-resolved terahertz spectroscopy}

The terahertz (THz) experiments were done using the same laser setup described in the previous paragraph (Legend-USP regenerative amplifier seeded by the Ti:sapphire oscillator). The amplified fundamental beam centered at $800 \mathrm{~nm}(50 \mathrm{fs}, 1 \mathrm{~W}, 1 \mathrm{kHz})$ was divided into three parts. The first one $(\sim 700 \mathrm{~mW})$ was directed through an OPA and additional 1-mm BBO crystal for frequency doubling to obtain $600 \mathrm{~nm}$ pulses. The resulting beam is sent through a long (up to $10 \mathrm{~ns}$ ) delay line ( $\mathrm{H} 2 \mathrm{~W}$ Technologies) to pump the sample in the time-resolved $\mathrm{THz}$ experiment. The second part of the amplified output beam $(\sim 200 \mathrm{~mW})$ generates the $\mathrm{THz}$ probe in a ZnTe crystal by optical rectification. The third part $(\sim 1 \mathrm{~mW})$ is used for electro-optic detection of the THz signal in another ZnTe crystal. During the measurements, the setup was continuously purged with dry nitrogen gas. The experiments are performed without any additional illumination and at $273 \mathrm{~K}$. The IRF of the setup is < $1 \mathrm{ps}$ [34].

\subsection{Flash Photolysis Spectroscopy}

The nanosecond (ns) flash photolysis experimental setup was described previously [35]. Briefly, it consists of an LKS.60 laser flash photolysis spectrometer (Applied Photophysics) 
and a Vibrant (HE) 355 II laser (Opotek). Pulses from Vibrant are used as an input of light for an optical parametric oscillator (OPO) pumped by a Q-switched Nd:YAG laser (Brilliant, Quantel) generating excitation pulses at $460 \mathrm{~nm}$. The probing light source is a $150 \mathrm{~W}$ xenon arc lamp. The light transmitted through the sample is dispersed by a monochromator and detected by visible photomultipliers (Applied Photophysics R928) coupled to a digital oscilloscope (Agilent Infiniium DS08064A, $600 \mathrm{MHz}, 4 \mathrm{GSa} / \mathrm{s}$ ). The measured IRF of the system is $\sim 8 \mathrm{~ns}$.

\section{Results and discussion}

\subsection{Morphology, structure and absorption spectra}

The morphology and structure of $\mathrm{MAPbI}_{3}$ and $\mathrm{MAPbI}_{3} / \mathrm{QDs}(6.3 \mathrm{wt} \%$, QDs size $~ 3 \mathrm{~nm})$ films were characterized by SEM (Figure S1, for wt\% calculation, see Equations S1). Both samples show comparable fine polycrystalline structure (grains size $\sim 30-100 \mathrm{~nm}$ ). The thicknesses of $\mathrm{MAPbI}_{3}$ and $\mathrm{MAPbI}_{3} / \mathrm{QDs}$ films are $80 \pm 10$ and $120 \pm 10 \mathrm{~nm}$, respectively. Proper perovskite crystalline structure of both samples was proved also using XRD technique (Figure S2a). Signal peaks at $14^{\circ}, 28^{\circ}$ and $32^{\circ}$ detected on $\mathrm{MAPbI}_{3}$ and $\mathrm{MAPbI}_{3} / \mathrm{QDs}$ correspond to $\{110\},\{220\}$ and $\{310\}$ atomic planes of $\mathrm{MAPbI}_{3}$, respectively $[19,27,36]$. Steady-state absorption spectra of $\mathrm{MAPbI}_{3}, \mathrm{MAPbI}_{3} / \mathrm{QDs}(6.3 \mathrm{wt} \%$ ) and QDs not attached to perovskite matrix are presented in Figure $\mathrm{S} 2 \mathrm{~b}$. The spectra of $\mathrm{MAPbI}_{3}$ and $\mathrm{MAPbI}_{3} / \mathrm{QD}$ are comparable and very similar to those already published on this type of perovskite [24, 37]. The presence of QDs is mainly manifested by differences in the absorption of $\mathrm{MAPbI}_{3}$ and $\mathrm{MAPbI}_{3} / \mathrm{QDs}$ films in the spectral region $>800 \mathrm{~nm}$.

\subsection{Femtosecond time-resolved transient absorption spectroscopy}

Time-resolved transient absorption (TA) spectroscopy was used to characterize and elucidate the charge carrier processes in excited $\mathrm{MAPbI}_{3} / \mathrm{QDs}$ films. To obtain a clear picture 
of the involved events, we have studied $\mathrm{MAPbI}_{3} / \mathrm{QDs}$ materials containing various QD concentrations $\left(\mathrm{C}_{\mathrm{QDs}}\right)$ : 0, 0.12, 0.18, 0.24, 0.30, 0.59, 1.2, 2.6, 4.6, 6.3 and $7.3 \mathrm{wt} \%$. Samples were excited at different excitation wavelengths: 400, 600, 700 and $740 \mathrm{~nm}$, using the constant fluence of the absorbed photons $8.2 \times 10^{12}$ photons per $\mathrm{cm}^{2}\left(\mathrm{ph} / \mathrm{cm}^{2}\right.$, for more detail, see Supplementary information). The fluence dependences of TA decays observed for $\mathrm{MAPbI}_{3} / \mathrm{QDs}(6.3$ and $0.3 \mathrm{wt} \%)$ are also presented $\left(600 \mathrm{~nm}, 1.5-16 \times 10^{12} \mathrm{ph} / \mathrm{cm}^{2}\right)$.

\subsubsection{Transient spectra and decays}

To begin with, we first show and discuss the results of neat perovskite and $\mathrm{MAPbI}_{3} / \mathrm{QDs}$ film containing $6.3 \mathrm{wt} \%$ of the QDs upon excitation at $600 \mathrm{~nm}$, using fluence of the absorbed photons $8.2 \times 10^{12} \mathrm{ph} / \mathrm{cm}^{2}$. The TA spectrum of $\mathrm{MAPbI}_{3}$ film consists of two photobleaching bands (PB) with intensity maxima located at approximately $480 \mathrm{~nm}(\mathrm{~PB} 1)$ and $763 \mathrm{~nm}(\mathrm{~PB} 2)$, and positive band (photoinduced absorption, PIA) in the region $520-700 \mathrm{~nm}$ (Figure 1a). This result is in agreement with previous reports on neat perovskite films [38-40]. The initial negative signal at $760 \mathrm{~nm}$ (PB2) shifts slightly towards longer wavelengths upon increasing pump-probe delay time (up to $700 \mathrm{fs}$ ) due to the band filling process (Figure S3a) [41-43]. No further spectral changes of PB2 were recorded. The TA spectra of the $\mathrm{MAPbI}_{3} / \mathrm{QDs}$ and $\mathrm{MAPbI}_{3}$ films exhibit the same features (Figures 1a and S3a,b). The only difference is a blueshift (5 nm) of $\mathrm{MAPbI}_{3} / \mathrm{QDs} \mathrm{PB} 2$ when compared to that of $\mathrm{MAPbI}_{3}$ one. The excitation of neat QDs film does not lead to the appearance of any TA signal in the visible region (under the same excitation conditions). Therefore, the observed spectral photobehavior of $\mathrm{MAPbI}_{3} / \mathrm{QDs}$ sample originates from excitation of perovskite domain and not from QDs excitation. This statement is also supported by the comparable initial TA signal of $\mathrm{MAPbI}_{3}$ and $\mathrm{MAPbI}_{3} / \mathrm{QDs}$ (Figure 1a). Consequently, the blue shift in the $\mathrm{PB} 2$ band of $\mathrm{MAPbI}_{3} / \mathrm{QDs}$ is due to changes in the electronic and/or crystallographic structure of $\mathrm{MAPbI}_{3}$ in presence of the QDs. Such modifications were 
observed after passivation by the QDs due to the lattice mismatch between the two materials $[18,21,44,45]$. The interpretation of the blue shift also agrees with reported band gap expansion of $\mathrm{MAPbI}_{3}$ related to structural deformation [46].

Figures 1b,c show the two-dimensional pseudo-color maps of the transient absorption signal of neat perovskite and $\mathrm{MAPbI}_{3} / \mathrm{QDs}$ in the visible regime. It can be seen that while the signal of both PIA and PB2 bands in the former sample stays up to the ns regime, those of $\mathrm{MAPbI}_{3} / \mathrm{QDs}$ strongly decrease in sub-ns. This clearly shows the influence of fast decaying channels in the transients of $\mathrm{MAPbI}_{3} / \mathrm{QDs}$. The dynamics of PIA and PB2 in the TAS of perovskite film are closely related $[38,40,47]$. Thus, to analyze the involved photoevents, we focus on PB2 fs-transients of both samples (gating at $760 \mathrm{~nm}$ ).

Figure 1d exhibits that the signal of excited $\mathrm{MAPbI}_{3}$ slowly decays losing approximately $35 \%$ of its initial value at $1.5 \mathrm{~ns}$. This behavior is caused by the presence of monomolecular (trap-assisted), bimolecular and Auger charge carrier deactivation processes [34, 42, 48-50]. It is known that the contribution of each process to the overall decay depends on perovskite composition and concentration of charge carriers. We have quantified the recombination rate constants of these events adopting a kinetic model applied previously for neat perovskite materials (Equation S3, for more details see Supplementary information) [40, 42, 51, 52]. The obtained values of the rate constants $\left(k_{\text {mono }}=1.6 \times 10^{7} \mathrm{~s}^{-1}, k_{\text {bimol }}=8.1 \times 10^{-11} \mathrm{~cm}^{3} \mathrm{~s}^{-1}\right.$ and $k_{\text {Auger }}=$ $2.9 \times 10^{-28} \mathrm{~cm}^{6} \mathrm{~s}^{-1}$ ) are comparable to previously published ones [51-53].

In contrast to the TA spectra, the decays of excited $\mathrm{MAPbI}_{3} / \mathrm{QDs}$ are significantly affected by the presence of QDs (Figure 1d). Except the long-lasting residual signal 10\% (after $1.2 \mathrm{~ns}$ ), the decay is being done within the first 200 ps (only $20 \%$ of the initial intensity is left after $100 \mathrm{ps}$ ). While the origin of this behavior will be discussed in more detail further, we briefly assign it to the following events. The fast decay is mainly caused by diffusion and subsequent transfer of the photoexcited holes from the perovskite valence band (VB) to the one 
of the QDs, and the electrons from perovskite conductive band (CB) to the $\mathrm{MAPbI}_{3} / \mathrm{QDs}$ interface. The residual signal is related to charge carriers in the perovskite domain of $\mathrm{MAPbI}_{3} / \mathrm{QDs}$, not affected by the presence of QDs. It is evident that charge carriers diffusion and transfer from $\mathrm{MAPbI}_{3}$ to QDs dominates the dynamics in this composite material (Figure S3c). A new kinetic model is necessary to analyze the photoevents, and related electrons and holes dynamics in the excited $\mathrm{MAPbI}_{3} / \mathrm{QDs}$ film.

Analyzing the short-time scale $(<1 \mathrm{ps})$, the TA signals of the $\mathrm{MAPbI}_{3}$ and $\mathrm{MAPbI}_{3} / \mathrm{QDs}$ (6.3 wt\%) show ultrafast rising components (Figure S3d). We were able to fit the rising part using a monoexponential function obtaining s time constant of $\sim 150$ fs for both $\mathrm{MAPbI}_{3}$ and $\mathrm{MAPbI}_{3} / \mathrm{QDs}$ films. Such behavior of the TA signal during the first $100 \mathrm{~s}$ fs after excitation is typical for perovskite materials, and it reflects hot charge carrier cooling [41, 54, 55]. Since we recorded the same risetime and comparable $\Delta \mathrm{OD}$ changes within 1 ps after excitation of both $\mathrm{MAPbI}_{3} / \mathrm{QDs}$ and $\mathrm{MAPbI}_{3}$ films, we conclude that in the sub-ps regime, the charge carrier dynamics in the perovskite domain is not affected by the presence of QD during the initial cooling phase in the $\mathrm{MAPbI}_{3} / \mathrm{QDs}$ film.

\subsubsection{Influence of QDs concentration}

To elucidate the effect of QDs presence on charge carriers deactivation, we have recorded and analyzed the TA decays of excited $\mathrm{MAPbI}_{3} / \mathrm{QDs}$ containing different $C_{\mathrm{QDs}}$. Figure 2 presents the TA decays (observed at $760 \mathrm{~nm}$ ) of the samples containing: $0,0.12,0.18,0.24$, $0.30,0.59,1.2,2.6,4.6,6.3$ and $7.3 \mathrm{wt} \%$ of QDs, under the same experimental conditions of excitation $\left(600 \mathrm{~nm}\right.$, fluence of the absorbed photons $\left.8.2 \times 10^{12} \mathrm{ph} / \mathrm{cm}^{2}\right)$. The samples were prepared under similar conditions (for more details, see the sample preparation in Materials and Methods). In agreement with the behavior shown in Figure 1d, the decays become shorter upon increasing $C_{\mathrm{QDs}}$. The most significant change starts from $C_{\mathrm{QDs}} \sim 0.24 \mathrm{wt} \%$. The TA decays 
of samples containing $C_{\mathrm{QDs}}$ lower than $0.18 \mathrm{wt} \%$ were governed by the behavior of neat perovskite. The dependence of TA decays on $C_{\mathrm{QDs}}$ clearly demonstrates that their shortening reflects a charge deactivation processes related to the presence of QDs in the film.

\subsection{Kinetic model for $\mathrm{MAPbI}_{3} / \mathrm{QDs}$}

\subsubsection{Description of the model}

To accurately analyze the observed dynamics, we propose the following model (Figure 3). Because the QDs do not occupy all the perovskite domain, we divided the probed part (width $\sim 100 \mu \mathrm{m}$ ) in two areas (Figure 3a): area where the photoexcited charges can be affected by the presence of QDs (domain 1, D1), and area (D2) where these carriers do not interact with the QDs. Figures 3a,b and c illustrate our concept, and the processes taking place in D1 and D2. Note that for clarity, the scheme in Figure $3 \mathrm{~b}$ is simplified, and in D1 the photoexcited population may still follow the dynamics described in Figure 3c.

To begin with, we describe the events happening in D1: $(i)$ charge carriers transport and transfer from perovskite domain to QDs and $\mathrm{MAPbI}_{3} / \mathrm{QDs}$ interface (Figure 3b), (ii) exciton recombination (Figure 3b), (iii) electron and hole recombination processes in perovskite (Figure 3c), and (iv) recombination of transferred charge carriers (Figure 3b).

(i) According to the reported energy diagram of $\mathrm{MAPbI}_{3}$ containing PbS/CdS QDs of 3 $\mathrm{nm}$ size, the CB and VB edges of perovskite and QDs are located at $-3.93 \mathrm{eV}$ and $-5.43 \mathrm{eV}$, and $-3.68 \mathrm{eV}$ and $-5.23 \mathrm{eV}$, respectively [23] [37]. Therefore, only holes can be easily transferred from the perovskite domain to QDs. The electrons deactivation can follow several paths. Firstly, because the initial energy of some excited electrons at $600 \mathrm{~nm}(2.1 \mathrm{eV})$ in the perovskite domain is higher than the energy difference between the edges of the VB in perovskite and the $\mathrm{CB}$ in QDs $(\sim 1.75 \mathrm{eV})$, the ultrafast transition of these hot charge carriers to the $\mathrm{CB}$ of the QDs is possible. However, the occurrence of this process is unlikely due to the 
presence of highly competitive ultrafast electron cooling in perovskite domain, which has much shorter time (<1 ps, Figure S3d) $[38,40]$ than that of TA decay in $\mathrm{MAPbI}_{3} / \mathrm{QDs} \quad(\sim 200-500$ ps, Figure 2). Secondly, the electrons in the CB of perovskite domain may recombine directly with the holes transferred to the QDs VB (via no vertical transitions). However, presence of such fast recombination process would be in contradiction with long and efficient PL conversion observed in this material [23]. Moreover, very similar spectral shapes and positions of the $\mathrm{PB} 2$ bands in the $\mathrm{MAPbI}_{3}$ and $\mathrm{MAPbI}_{3} / \mathrm{QDs}$ films suggest that the ultrafast electron-hole recombination occurs mostly in the perovskite domain. Thirdly, electrons can be transferred and subsequently trapped in perovskite/QDs interface. Indeed, it has been reported that, in the presence of QDs, the crystallographic structure of the $\mathrm{MAPbI}_{3}$ lattice might be different inside the crystallite and at the interface with the QDs, thus, new trap states will appear [18, 21, 44]. The presence of interfacial electron trap states in $\mathrm{MAPbI}_{3} / \mathrm{PbS}$ was also proved by the density functional theory calculations [18]. This conclusion is in agreement with our steady-state absorption measurements in the near IR region (the absorption of $\mathrm{MAPbI}_{3} / \mathrm{QDs}$ at $>800 \mathrm{~nm}$, Figure S2b). It is important to note that before the carriers can be transferred, they need to be transported to $\mathrm{MAPbI}_{3} / \mathrm{QDs}$ interface first. Therefore, not only the transfer processes affect the fact deactivation of charges in D1, but also the transport time of charge carriers. We label the combination of both these effects as effective charge carrier transfer.

(ii) It is well known that the binding energy of excitons in $\mathrm{MAPbI}_{3}$ is below the thermal energy at ambient conditions $(25.7 \mathrm{meV})$ that should lead to efficient formation of free charge carriers as a result of the photoexcitation [52]. However, the changes in the perovskite lattice in the close vicinity of QDs, can induce and increase localization of photoexcited charges, related excitons bounding energy and Langevin coefficient $[56,57]$. This may result in an initial formation of excitons able to survive several picoseconds without dissociation in the close vicinity of QD. We believe that this behavior is the origin of the observed initial fast TA decay 
(first few ps) of excited $\mathrm{MAPbI}_{3} / \mathrm{QDs}$ film (Figure S3c) [34]. Appearance of the interface structural defects in $\mathrm{MAPbI}_{3} / \mathrm{QDs}$ films were already discussed in Section 3.2.1. The presence of excitons was also verified by the fluence dependence of TA decays and comparison of $\mathrm{THz}$ measurements of $\mathrm{MAPbI}_{3} / \mathrm{QDs}$ that show the absence of the initial fast signal decrease (vide intra, Section 3.7.). This agrees with the reports of TA signal decay in neat $\mathrm{PbS} / \mathrm{CdS}$ quantum dots, interpreted on the basis of a surface exciton deactivation model [58].

(iii) For the fast and efficient charge deactivation in $\mathrm{MAPbI}_{3} / \mathrm{QDs}$, the recombination processes (monomolecular trap-assisted, bimolecular and Auger) normally happening in neat perovskite should be significantly suppressed. However, they are still present where the charge carriers are part of perovskite domain.

(iv) The transferred holes and trapped interfacial electrons can recombine through trapassisted processes. However, radiative recombination between both types of transferred carriers is more likely. This assumption is in agreement with recent observation of a new NIR luminescence peak when perovskite and $\mathrm{PbS} / \mathrm{CdS}$ QDs are combined [23]. The energy of the emitted photons corresponds to the difference between positions of shallow electron traps at the $\mathrm{MAPbI}_{3} / \mathrm{QDs}$ interface and QDs VB.

Now, we describe the processes in D2 (Figure 3). The TA decays show a residual signal at times longer than several 100s ps (Figure 1d). Because, the signal gated at $760 \mathrm{~nm}$ is mainly sensitive to the charges in perovskite, this signal is most probably caused by the photoexcited charges (in D2) not transferred to the interface or QDs interior. Their presence in the perovskite domain might by due to their low mobility (e.g. trapped in shallow states of perovskite band gap) or lack of interaction with QDs $[34,46,59]$. However, the comparable features of TA and THz signals suggest that these charges keep their mobility during the gating time (up to $1.5 \mathrm{~ns}$ ). Thus, the latter explanation seems to be the most plausible one (vide intra, Sections 3.4. and 3.7.). These charges should follow standard perovskite recombination processes (Equation S3). 
In addition to the discussed processes above, the electron transfer from QDs to $\mathrm{MAPbI}_{3} / \mathrm{QDs}$ is also possible. However, taking into account the absence of TA signal of neat QDs layers, and comparable initial TA values of excited neat perovskite and $\mathrm{MAPbI}_{3} / \mathrm{QDs}$ at $760 \mathrm{~nm}$, the contribution of such transfer to the signal should be negligible.

\subsubsection{Mathematical model}

To quantify the processes in D1, we propose a following set of kinetic equations based on previous information [59-61]:

$$
\begin{gathered}
\frac{d n_{e}}{d t}=G_{e}-n_{e} k_{\text {mono }}-n_{e} n_{h} k_{\text {bimol }}-n_{e}{ }^{2} n_{h} k_{\text {auger }}-n_{e} k_{\text {etrans }} \\
\frac{d n_{h}}{d t}=G_{h}-n_{h} k_{\text {mono }}-n_{e} n_{h} k_{\text {bimol }}-n_{h}{ }^{2} n_{e} k_{\text {auger }}-n_{h} k_{\text {htrans }} \\
\frac{d n_{x}}{d t}=G_{x}-k_{x} n_{x} \\
\frac{d n_{\text {interface }}}{d t}=+n_{e} k_{\text {etrans }}-n_{\text {interface }} n_{Q D} k_{Q D I n} \\
\frac{d n_{Q D}}{d t}=+n_{h} k_{\text {htrans }}-n_{\text {interface }} n_{Q D} k_{Q D I n}
\end{gathered}
$$

where $n_{\mathrm{e}}, n_{\mathrm{h}}$ and $n_{\mathrm{x}}$ are the concentrations of free electrons and holes in CB and VB of perovskite domains, and excitons in the perovskite domain in close vicinity of the interface, respectively. $G_{\mathrm{e}}, G_{\mathrm{h}}$ and $G_{\mathrm{x}}$ refer to the generation factors of these entities. According to this model, the overall generation factor, $G$, should be equal to the sum of the generation factors of free charges and excitons. The effective transfer rate constants of holes to QDs and electrons to $\mathrm{MAPbI}_{3} / \mathrm{QDs}$ interface are given by $k_{\mathrm{htrans}}$ and $k_{\text {etrans, }}$, respectively; while the recombination rate constant of excitons is described by $k_{\mathrm{x}}$. The $n_{\text {interface }}$ and $n_{\mathrm{QD}}$ reflect the concentrations of electrons trapped in the interface and holes transferred to the VB of QDs, respectively. The recombination rate constant of these two carriers is given by $k_{\mathrm{QDIn}}$. However, because the TA signal at $760 \mathrm{~nm}$ is only sensitive to the charge carriers in the perovskite domain, and we did not observe any TA signal from QDs, we are not able to determine the value of $k_{\mathrm{QDIn}}$. 
The overall decay of observed TA signal should be given by the sum of those in D1 and D2:

$$
\text { TA signal }=n_{\text {total }}(t)=P_{D 1}\left(n_{e}(t)+n_{h}(t)+n_{x}(t)\right)+P_{D 2} n(t)
$$

$P_{\mathrm{D} 1}$ and $P_{\mathrm{D} 2}$ characterize the population fractions of charge carriers in D1 and D2 areas. We call $n(\mathrm{t})$ the population of the charge carriers in D2, as described in Equation S3. To simplify the model, we did not take into account the ultrafast dynamics of charge carrier generation, their thermalization and cooling. These events happening commonly in less than 1 ps [52].

\subsubsection{Analysis of the transient absorption decays}

Figure 2 shows the fits of the TA decays using the kinetic model, and Table 1 gives the obtained data from the best fits (for TA decays converted to charge carrier concentration, see Figure S4). The values of $k_{\text {mono }}, k_{\text {bimol }}$ and $k_{\text {Auger }}$ used in the fits were taken from the analysis of the photobehavior of neat perovskite and related known model (for more information about the of the model, see Supplementary information) [60, 61].

Firstly, we discuss the observed dependence of $k_{\text {htrans }}$ and $k_{\text {etrans }}$ values on $C_{Q D s}$ (Table 1). The dependence is visualized in the Figure S5. It is clear that upon increasing the $C_{\mathrm{QDs}}(0.24$ to $7.3 \mathrm{wt} \%)$ the values of $k_{\text {htrans }}$ and $k_{\text {etrans }}\left(10^{10} \mathrm{~s}^{-1}\right)$ increase from 0.81 to 4.6 and from 0.22 to 1.2 , respectively. While the probability of carrier transfer should be independent on $C_{\mathrm{QDs}}$, the observed dependence can be explained by a change in charge carrier diffusion time before reaching QDs. According to the diffusion theory [62] and Wigner-Seitz radius calculation [63], both effective transfer rate constants should be proportion to $C_{\mathrm{QDs}}{ }^{2 / 3}$ (see Supplementary information, Equations S4-6). Figure S5 shows the agreement of the observation with the theory. The ratio of the $k_{\text {htrans }} / k_{\text {etrans }}$ is constant and equal to approximately 4 in the wide range of $C_{\mathrm{QDs}}\left(7.3-0.24 \mathrm{wt} \%\right.$, Figure S5 inset). Two remarks: $(i)$ its independence on $C_{\mathrm{QDs}}$ is in agreement with the diffusion theory. (ii) Its value reflects a combined effect of higher transfer 
efficiency of holes to QDs VB, in contrast to the electrons transfer to interface states and small differences in charge carriers mobilities (see Supplementary information). $k_{\text {htrans }}$ and $k_{\text {etrans }}$ rate constants behavior for $C_{\mathrm{QDs}}<0.24 \mathrm{wt} \%$ is not discussed because of the strong signal from the neat perovskite.

Secondly, the fitting parameters (Table 1) suggest that $92 \%$ all charge carriers in $\mathrm{MAPbI}_{3} / \mathrm{QDs}(7.3 \mathrm{wt} \%)$ film should be generated in D1. This value slightly decreases to $88 \%$ for sample containing $0.24 \mathrm{wt} \%$ of QDs. The fitting also shows comparable concentrations of photoexcited holes and electrons (52:48) in D1, suggesting that no ultrafast and fast interaction of photoexcited charges with traps or dark carriers is the present in $\mathrm{MAPbI}_{3} / \mathrm{QDs}$ films. The sample with low $C_{\mathrm{QDs}}(<0.18 \mathrm{wt} \%)$ showed only weak contribution of D1 region causing a weak acceleration of perovskite-like TA decay.

The analysis also shows that the population fraction of the excitons $\left(P_{\mathrm{x}}\right)$ in D1 depends on $C_{\mathrm{QDs}}$. The $P_{\mathrm{x}}$ is $7 \%$ for the sample with the highest QDs concentration and vanishes at $C_{\mathrm{QDs}}$ lower than $4.6 \mathrm{wt} \%$. Considering that the excitonic states are located in close vicinity of QDs, this result is in agreement with our model. The value of $k_{\mathrm{x}}$ is almost constant in all samples ( $\left.3.5 \times 10^{11} \mathrm{~s}^{-1}\right)$

\subsection{Transient absorption: fluence dependence}

To support the kinetic model, we measured the TA decays of $\mathrm{MAPbI}_{3} / \mathrm{QDs}$ films containing high (6.3 wt \%) and low $(0.3 \mathrm{wt} \%)$ concentration of QDs, using different fluences of the absorbed photons. Figure 4a shows the decay of TA signal converted to the concentration of charge carriers of $\mathrm{MAPbI}_{3} / \mathrm{QDs}(6.3 \mathrm{wt} \%)$ upon excitation at $600 \mathrm{~nm}$, using fluences of the absorbed photons: $1.5 \times 10^{12}, 8.2 \times 10^{12}$ and $16 \times 10^{12} \mathrm{ph} / \mathrm{cm}^{2}$. The similarity of the decays proves that non-monomolecular deactivation channels are significantly closed, and the electron/hole deactivation processes should be primarily driven by the interaction between the perovskite and 
QDs (Figure S6a). In fact, bimolecular and especially the Auger processes are fluence dependent, and thus their contribution would cause significant shortening of the TA decays at a higher fluence of the excitation [48]. It is noteworthy that the amount of charge carriers responsible for the TA residual signal at longer times (> $400 \mathrm{ps}$ ) increases almost linearly with the fluence, and does not saturate even at the used highest fluences of the absorbed photons. Thus, these carriers should not be related to the localized states in perovskite domain, but they are more likely free charge carriers not affected by QDs. In fact, concentration of trap states in perovskite domain was reported to be lower than photons absorbed per laser pulse using highest pump fluence [52]. The only difference between the recorded decays is their small shortening within the first $\sim 5 \mathrm{ps}$, when decreasing the fluence of the absorbed photons (Figure $4 \mathrm{a}$, inset). While the influence of bimolecular or Auger processes would have exactly opposite effect, this behavior is also suggesting the suppression of higher order processes in $\mathrm{MAPbI}_{3} / \mathrm{QDs}$ [48]. We interpret this behavior in terms of rapid deactivation of charges related to limited amount of states that show saturation under stronger excitation. This is in agreement with our suggestion of excitonic states presence in perovskite domain of $\mathrm{D} 1$ in close vicinity to the $\mathrm{MAPbI}_{3} / \mathrm{QDs}$ interface. All the decays in Figure 4a were successfully fitted using the proposed kinetic model. The obtained data are shown in Table S1. Taking into account that doubling the fluence of the absorbed photons from $8.2 \times 10^{12}$ to $16 \times 10^{12} \mathrm{ph} / \mathrm{cm}^{-2}$ causes only small increase of exciton amount in $\mathrm{MAPbI}_{3} / \mathrm{QDs}(6.3 \mathrm{wt} \%)$, the concentration of excitonic states in this sample can be estimated as $\sim 5 \times 10^{16} \mathrm{~cm}^{-3}$.

Comparable results were observed for $\mathrm{MAPbI}_{3} / \mathrm{QDs}$ containing low $C_{\mathrm{QDs}}(0.30 \mathrm{wt} \%)$ (Figure 4b, S6b and Table S1). However, as the inset of Figure 4b shows, there is no variation of the decays with excitation fluence at short time regime indicating a lack of excitons (low $\left.C_{\mathrm{QDs}}\right)$. 
The risetimes of the $\mathrm{MAPbI}_{3} / \mathrm{QDs}(6.3 \mathrm{wt} \%)$ TA signal increases from 110 to $230 \mathrm{fs}$ (longer than the IRF $\sim 70 \mathrm{fs}$ ) when the fluence of the absorbed photons varies from $1.5 \times 10^{12}$ to $16 \times 10^{12} \mathrm{ph} / \mathrm{cm}^{2}$ (Figure S6c, Table S2). The observed behavior is not caused by QDs presence, but it is the result of state saturation and the phonon bottleneck processes happening in perovskite as it has been previously reported $[41,54,55]$. This explanation is also supported by the very similar behavior of the neat perovskite film (Figure S6d, Table S2).

\subsection{Transient absorption: excess energy of excitation}

To elucidate the role of the excess energy of the photogenerated charge carriers on their transport and recombination mechanisms in $\mathrm{MAPbI}_{3} / \mathrm{QDs}$, we have analyzed the TA decays of $\mathrm{MAPbI}_{3} / \mathrm{QDs}(6.3 \mathrm{wt} \%)$ upon excitation at $400(3.1 \mathrm{eV}), 600(2.1 \mathrm{eV}), 700(1.8 \mathrm{eV})$, and 740 $\mathrm{nm}(1.7 \mathrm{eV})$ (all over band gap excitations). The TA signal was observed at $760 \mathrm{~nm}$. The fluence of the absorbed photons was fixed at $8.2 \times 10^{12} \mathrm{ph} / \mathrm{cm}^{2}$, and the result is shown in Figure S7. In contrast to the excitation with the lowest energy $(740 \mathrm{~nm})$, the first three excitations are able to create hot electrons with energy higher than that of QDs CB $(\sim 1.75 \mathrm{eV})$. The TA decays show similar behaviors independently on the excess energy, suggesting no apparent transfer of hot electrons from perovskite domain to QDs CB within the temporal resolution of our experiments (Table S3). In addition to that, we observed an increase in the TA rising time from 70 to $420 \mathrm{fs}$ when increasing the excess energy of the charge carriers (Figure S7 inset and Table S4). This effect is due to cooling of hot charge carriers in perovskite, and it is not caused by the presence of QDs, as we explained above [38, 40].

\subsection{Flash photolysis}

To get information on the longer-lived species, we used the nanosecond-millisecond flash photolysis technique. We excited the films at $460 \mathrm{~nm}$ and observed the decays at $580 \mathrm{~nm}$. For the $\mathrm{MAPbI}_{3}$ film, the fit of the decays requires two exponential components showing time 
constants of $\tau_{P 1}=50 \mathrm{~ns}$ and $\tau_{P 2}=560 \mathrm{~ns}$, which are attributed to the recombination of the trapped charge carriers from the surface and the internal trap states of perovskite crystals, respectively (Figure S8). These results are in agreements with previous reports [12, 40, 52, 64]. However, accurate multi-exponential fit of the $\mathrm{MAPbI}_{3} / \mathrm{QDs}(6.3 \mathrm{wt} \%)$ decay needs four components: two of them are similar to those of neat perovskite ( $\tau_{\mathrm{P} 1}=50 \mathrm{~ns}$ and $\left.\tau_{\mathrm{P} 2}=560 \mathrm{~ns}\right)$, and two others in the microsecond regime $\left(\tau_{\mathrm{P} 3}=3.8 \mu \mathrm{s}\right.$ and $\left.\tau_{\mathrm{P} 4}=45 \mu \mathrm{s}\right)$. The appearance of these additional components is a result of the interactions between both materials, allowing longer deactivation processes which could be attributed to the transitions involving the electrons states on the interface, holes in QDs and exciplex states [23]. The presence of long lived interface states is also in good agreement with proposed mechanisms of photoexcited electron transfer.

\subsection{Time-resolved Terahertz Spectroscopy}

The charge carrier mobility and its time evolution are key parameters shaping the efficiency of optoelectronic devices. Therefore, we used ultrafast time-resolved $\mathrm{THz}$ spectroscopy to explore the dynamics of photoconductivity in neat $\mathrm{MAPbI}_{3}$ and $\mathrm{MAPbI}_{3} / \mathrm{QDs}$ (IRF $<1 \mathrm{ps}$ ). To begin with, Figure S9a presents the photoconductivity decays of the $\mathrm{MAPbI}_{3}$ film upon excitation at $600 \mathrm{~nm}$, using a fluence of the absorbed photons of $8.2 \times 10^{12} \mathrm{ph} / \mathrm{cm}^{2}$. The initial mobility has s value of $16.5 \mathrm{~cm}^{2} \mathrm{~V}^{-1} \mathrm{~s}^{-1}$, which is in the range of previously reported results for this material (for mobility calculation, see Supplementary information, Equation S7) [65-67]. The THz decays show similar temporal evolution as the TA signal of neat perovskite in the 1.5 ns time window (Figure S9a). This result indicates that only a change in charge carrier population is responsible for the photoconductivity decrease [34]. Thus, we converted the $\mathrm{THz}$ signal to charge carrier concentration, and fitted the decay using the known kinetic model for perovskite (Equation S3) obtaining, $k_{\text {mono }}=1.6 \times 10^{7} \mathrm{~s}^{-1}, k_{\text {bimol }}=1 \times 10^{-10} \mathrm{~cm}^{3} \mathrm{~s}^{-1}$ and $k_{\text {Auger }}=$ $2.9 \times 10^{-28} \mathrm{~cm}^{6} \mathrm{~s}^{-1}$. 
Figure 5a shows the fluence dependence of the photoconductivity decays in the $\mathrm{MAPbI}_{3} / \mathrm{QDs}$ film $(6.3 \mathrm{wt} \%)$ under experimental conditions similar to those used for neat perovskite film. The excitation of neat $\mathrm{PbS} / \mathrm{CdS}$ QD layer under conditions similar to those used for $\mathrm{MAPbI}_{3} / \mathrm{QDs}$ does not lead to a detectable photoconductivity, which indicates that the measured photoresponse of the latter is due to the photoconductivity signal in the perovskite. The values of the initial charge carrier mobilities using different fluences of the absorbed photons $\left(1.5-16 \times 10^{12} \mathrm{ph} / \mathrm{cm}^{2}\right)$ are similar to that in the neat perovskite and ranges from $15-$ $21 \mathrm{~cm}^{2} \mathrm{~V}^{-1} \mathrm{~s}^{-1}$. These results reflect the limited influence of QDs on the initial concentration and properties of the electrons and holes, in agreement with the TA data (Figure 1a, S3d). The only difference between the TA and THz decays of $\mathrm{MAPbI}_{3} / \mathrm{QDs}$ (Figure $5 \mathrm{~b}$ ) is the absence of the 3-ps decaying component in the THz signal (Figure 5b inset). This absence cannot be caused by the different risetimes of $\mathrm{TA}$ and $\mathrm{THz}$ signal that are also related to the IRFs of both techniques (TA $\sim 70 \mathrm{fs}, \mathrm{THz} \leq 1 \mathrm{ps}$ ), because similar behavior was not observed in the case of neat perovskite film (Figure S9a inset). While, charge carriers in excitonic form show negligible photoconductivity, also these measurements suggest the presence of fast dissociating excitons in $\mathrm{MAPbI}_{3} / \mathrm{QDs}$ film. Comparable difference between decays of TA and THz signals was previously observed in formamidinium lead triiodide, and also interpreted in terms of excitons presence $[48,68]$. Moreover, comparable magnitude of the normalized TA and THz residual signals suggests high mobility of charge carriers even at the later stage of the decays and supports the concept of $\mathrm{D} 2$ area within $\mathrm{MAPbI}_{3} / \mathrm{QDs}$. We also converted the photoconductivity decay of $\mathrm{MAPbI}_{3} / \mathrm{QDs}$ to charge carrier concentration, and analyzed it using our kinetic model (Figure 5a, S9b, Table S1). The obtained parameters are similar to those using the TA technique, only lacking the ultrafast excitonic component.

The obtained values of charge carrier mobilities in neat perovskite and $\mathrm{MAPbI}_{3} / \mathrm{QDs}$, and related rate constants of charge deactivation processes, using TA results, were used to 
calculate the diffusion lengths $L_{\mathrm{D}}$ of these carriers (for more information, see Supplementary information, Equation S8-9). The results are in Table S5, where the $L_{\mathrm{D}}$ increases from 38 to 87 nm, when $C_{\mathrm{QDs}}$ in $\mathrm{MAPbI}_{3} / \mathrm{QDs}$ decreases from 7.3 to $0.24 \mathrm{wt} \%$. The values of $L_{\mathrm{D}}$ are significantly lower than that of neat perovskite film $(318 \mathrm{~nm})$. This result is in full agreement with the presence of additional deactivation sides (QDs) in the hybrid material. The $L_{\mathrm{D}}$ in neat perovskite film is within the range of reported values $(105-460 \mathrm{~nm})[38,69,70]$.

Optimization of any kind of optoelectronic device demands the reduction or suppression of non-radiative recombination processes. We have shown that ultrafast characterization of promising perovskite/QD systems for new LEDs fabrication provides key information on the electron and hole dynamics. Further development of perovskite/QD hybrid materials requires reduction of non-radiative recombination at the perovskite grains and the perovskite/QDs interfaces. This optimization will require the control of interfacial defects at the surfaces of both perovskite and QDs. Different methods could be explored to attain this objective, including the passivation of defects using chemical surface engineering, photon curing control and a further development of the methods to embed the QDs within the perovskite material.

\section{Conclusions}

In summary, we have characterized the ultrafast dynamics of photoexcited charge carrier transfer and recombination processes in a $\mathrm{MAPbI}_{3}$ thin polycrystalline film containing $\mathrm{PbS} / \mathrm{CdS}$ (core/shell) QDs using ultrafast time-resolved transient visible-NIR absorption and terahertz spectroscopies. We used a kinetic model to analyze the complex behavior of this promising hybrid material for electro-optical devices. We observed that $85-89 \%$ of both electrons and holes were transferred to the perovskite/QDs interface trap states, and to the valence band $(\mathrm{VB})$ of the QDs with effective transfer rate constants of $0.22-1.2 \times 10^{10} \mathrm{~s}^{-1}(83$ $-455 \mathrm{ps})$ and $0.81-4.6 \times 10^{10} \mathrm{~s}^{-1}(22-123 \mathrm{ps})$, respectively. Up to $7 \%$ charges formed excitons 
in perovskite domain in the close vicinity of interface showing recombination rate constant of $3.7 \times 10^{11} \mathrm{~s}^{-1}(3 \mathrm{ps})$. A small fraction of photoexcited charges $(8-15 \%)$ were not affected by the presence of QDs, and thus, their deactivation followed the standard processes of neat perovskite. The changes in the values are related to the QDs concentration of the matrix. We observed that towering the QDs concentration from 7.3 to $0.24 \mathrm{wt} \%$ increases the carrier decrease the values of charge carrier effective transfer rate constants to the interface and QDs, and the concentration of excitons. No significant variation in the charge carrier dynamics upon excitation at different energy levels was detected. While the initial $(<1 \mathrm{ps})$ mobility of charge carriers was not affected by the addition of embedded QDs, the photoconductivity decay was remarkably faster in contrast to the behavior in neat perovskite. The analysis of the data shows the important role of trap states and gives clues for the further improvement of this hybrid system. In addition to that the observation of the preservation of the initial charge carrier mobility like in perovskite film is a very important result highlighting the potentiality of this system in different applications of energy saving. The results here provide clear hints to improve the performance of electronic devices (solar cells, LEDs, photodetectors, etc.) by optimization of QDs concentration and by the passivation of the perovskite/QD interface.

\section{Acknowledgements}

This work was supported by Ministry of Economy and Competitiveness in Spain [MAT201457646-P, MAT2016-76892-C3-1-R], Junta de Comunidades de Castilla-La Mancha in Spain [PEII-2014-003-P], and European Research Council (ERC) via Consolidator Grant (724424 No-LIMIT). 


\section{References}

[1] Tang, J.; Liu, H.; Zhitomirsky, D.; Hoogland, S.; Wang, X.; Furukawa, M.; Levina, L.; Sargent, E. H., Nano Lett. 2012, 12 (9), 4889-4894.

[2] Chuang, C.-H. M.; Brown, P. R.; Bulovic, V.; Bawendi, M. G., Nat. Matter. 2014, 13 (8), 796801.

[3] Kershaw, S. V.; Jing, L.; Huang, X.; Gao, M.; Rogach, A. L., Mater. Horiz. 2017, 4 (2), 155205.

[4] Veldhuis, S. A.; Boix, P. P.; Yantara, N.; Li, M.; Sum, T. C.; Mathews, N.; Mhaisalkar, S. G., Adv. Mater. 2016, 28 (32), 6804-6834.

[5] Zuo, C.; Bolink, H. J.; Han, H.; Huang, J.; Cahen, D.; Ding, L., Adv. Sci. 2016, 3 (7), $1500324-$

n/a.

[6] Huber, D.; Reindl, M.; Huo, Y.; Huang, H.; Wildmann, J. S.; Schmidt, O. G.; Rastelli, A.; Trotta, R., Nat. Comm. 2017, 8, 15506.

[7] Wang, H.; Kubo, T.; Nakazaki, J.; Kinoshita, T.; Segawa, H., J. Phys. Chem. Lett. 2013, 4 (15), 2455-2460.

[8] Fan, F.; Voznyy, O.; Sabatini, R. P.; Bicanic, K. T.; Adachi, M. M.; McBride, J. R.; Reid, K. R.; Park, Y.-S.; Li, X.; Jain, A.; Quintero-Bermudez, R.; Saravanapavanantham, M.; Liu, M.; Korkusinski, M.; Hawrylak, P.; Klimov, V. I.; Rosenthal, S. J.; Hoogland, S.; Sargent, E. H., Nature 2017, 544 (7648), 75-79.

[9] Laboratory, N. R. E. https://www.nrel.gov/pv/assets/images/efficiency-chart.png.

[10] Wang, N.; Cheng, L.; Ge, R.; Zhang, S.; Miao, Y.; Zou, W.; Yi, C.; Sun, Y.; Cao, Y.; Yang, R.; Wei, Y.; Guo, Q.; Ke, Y.; Yu, M.; Jin, Y.; Liu, Y.; Ding, Q.; Di, D.; Yang, L.; Xing, G.; Tian, H.; Jin, C.; Gao, F.; Friend, R. H.; Wang, J.; Huang, W., Nat. Photon. 2016, 10 (11), 699-704.

[11] Xiao, Z.; Kerner, R. A.; Zhao, L.; Tran, N. L.; Lee, K. M.; Koh, T.-W.; Scholes, G. D.; Rand, B. P., Nat. Photon. 2017, 11 (2), 108-115.

[12] Zhu, H.; Fu, Y.; Meng, F.; Wu, X.; Gong, Z.; Ding, Q.; Gustafsson, M. V.; Trinh, M. T.; Jin, S.; Zhu, X. Y., Nat. Mater. 2015, 14 (6), 636-642.

[13] Shrestha, S.; Fischer, R.; Matt, G. J.; Feldner, P.; Michel, T.; Osvet, A.; Levchuk, I.; Merle, B.; Golkar, S.; Chen, H.; Tedde, S. F.; Schmidt, O.; Hock, R.; Rührig, M.; Göken, M.; Heiss, W.; Anton, G.; Brabec, C. J., Nat. Photon. 2017, 11 (7), 436-440.

[14] Zhang, L.; Yang, X.; Jiang, Q.; Wang, P.; Yin, Z.; Zhang, X.; Tan, H.; Yang, Y.; Wei, M.; Sutherland, B. R.; Sargent, E. H.; You, J., Nat. Comm. 2017, 8, 15640.

[15] Su, R.; Diederichs, C.; Wang, J.; Liew, T. C. H.; Zhao, J.; Liu, S.; Xu, W.; Chen, Z.; Xiong, Q., Nano Lett. 2017, 17 (6), 3982-3988.

[16] Liu, P.; He, X.; Ren, J.; Liao, Q.; Yao, J.; Fu, H., ACS Nano 2017, 11 (6), 5766-5773.

[17] Odenthal, P.; Talmadge, W.; Gundlach, N.; Wang, R.; Zhang, C.; Sun, D.; Yu, Z.-G.; Valy Vardeny, Z.; Li, Y. S., Nat. Phys. 2017, 13 (9), 894-899.

[18] Ning, Z. J.; Gong, X. W.; Comin, R.; Walters, G.; Fan, F. J.; Voznyy, O.; Yassitepe, E.; Buin, A.; Hoogland, S.; Sargent, E. H., Nature 2015, 523 (7560), 324-328.

[19] Li, S.-S.; Chang, C.-H.; Wang, Y.-C.; Lin, C.-W.; Wang, D.-Y.; Lin, J.-C.; Chen, C.-C.; Sheu, H.-S.; Chia, H.-C.; Wu, W.-R.; Jeng, U. S.; Liang, C.-T.; Sankar, R.; Chou, F.-C.; Chen, C.-W., Energy Environ. Sci. 2016, 9 (4), 1282-1289.

[20] Seo, G.; Seo, J.; Ryu, S.; Yin, W.; Ahn, T. K.; Seok, S. I., J. Phys. Chem. Lett. 2014, 5 (11), 2015-2020.

[21] Yang, Z. Y.; Janmohamed, A.; Lan, X. Z.; de Arquer, F. P. G.; Voznyy, O.; Yassitepe, E.; Kim, G. H.; Ning, Z. J.; Gong, X. W.; Comin, R.; Sargent, E. H., Nano Lett. 2015, 15 (11), 7539-7543.

[22] Lan, X.; Voznyy, O.; García de Arquer, F. P.; Liu, M.; Xu, J.; Proppe, A. H.; Walters, G.; Fan, F.; Tan, H.; Liu, M.; Yang, Z.; Hoogland, S.; Sargent, E. H., Nano Lett. 2016, 16 (7), 4630-4634.

[23] Sanchez, R. S.; de la Fuente, M. S.; Suarez, I.; Munoz-Matutano, G.; Martinez-Pastor, J. P.; Mora-Sero, I., Sci. Adv. 2016, 2 (1), 1501104.

[24] Ngo, T. T.; Suarez, I.; Sanchez, R. S.; Martinez-Pastor, J. P.; Mora-Sero, I., Nanoscale 2016, 8 (30), 14379-14383. 
[25] Gong, X.; Yang, Z.; Walters, G.; Comin, R.; Ning, Z.; Beauregard, E.; Adinolfi, V.; Voznyy, O.; Sargent, E. H., Nat. Photon. 2016, 10 (4), 253-257.

[26] García de Arquer, F. P.; Gong, X.; Sabatini, R. P.; Liu, M.; Kim, G.-H.; Sutherland, B. R.; Voznyy, O.; Xu, J.; Pang, Y.; Hoogland, S.; Sinton, D.; Sargent, E., Nat. Comm. 2017, 8, 14757.

[27] Yang, Y.; Wang, W. Y., J. Power Sources 2015, 293, 577-584.

[28] Kagan, C. R.; Murray, C. B., Nat. Nanotechnol. 2015, 10 (12), 1013-1026.

[29] Kovalenko, M. V.; Scheele, M.; Talapin, D. V., Science 2009, 324 (5933), 1417-1420.

[30] Kang, M. S.; Sahu, A.; Norris, D. J.; Frisbie, C. D., Nano Lett. 2010, 10 (9), 3727-3732.

[31] Yu, D.; Wehrenberg, B. L.; Jha, P.; Ma, J.; Guyot-Sionnest, P., J. Appl. Phys. 2006, 99 (10).

[32] Sanchez, R. S.; Binetti, E.; Torre, J. A.; Garcia-Belmonte, G.; Striccoli, M.; Mora-Sero, I., Nanoscale 2014, 6 (15), 8551-8555.

[33] Ziolek, M.; Tacchini, I.; Martinez, M. T.; Yang, X.; Sun, L.; Douhal, A., Phys. Chem. Chem. Phys. 2011, 13 (9), 4032-4044.

[34] Piatkowski, P.; Cohen, B.; Ponseca, C. S., Jr.; Salado, M.; Kazim, S.; Ahmad, S.; Sundstrom, V.; Douhal, A., J. Phys. Chem. Lett. 2016, 7 (1), 204-210.

[35] Ziółek, M.; Martín, C.; Sun, L.; Douhal, A., J. Phys. Chem. C 2012, 116 (50), 26227-26238.

[36] Baikie, T.; Fang, Y.; Kadro, J. M.; Schreyer, M.; Wei, F.; Mhaisalkar, S. G.; Graetzel, M.; White, T. J., J. Mater. Chem. A 2013, 1 (18), 5628-5641.

[37] Kim, H.-S.; Lee, C.-R.; Im, J.-H.; Lee, K.-B.; Moehl, T.; Marchioro, A.; Moon, S.-J.; HumphryBaker, R.; Yum, J.-H.; Moser, J. E.; Graetzel, M.; Park, N.-G., Sci. Rep. 2012, 2.

[38] Xing, G.; Mathews, N.; Sun, S.; Lim, S. S.; Lam, Y. M.; Graetzel, M.; Mhaisalkar, S.; Sum, T. C., Science 2013, 342 (6156), 344-347.

[39] Hsu, H.-Y.; Wang, C.-Y.; Fathi, A.; Shiu, J.-W.; Chung, C.-C.; Shen, P.-S.; Guo, T.-F.; Chen, P.; Lee, Y.-P.; Diau, E. W.-G., Angew. Chem. Int. Ed. 2014, 53 (35), 9339-9342.

[40] Piatkowski, P.; Cohen, B.; Ramos, F. J.; Di Nunzio, M.; Nazeeruddin, M. K.; Graetzel, M.; Ahmad, S.; Douhal, A., Phys. Chem. Chem. Phys. 2015, 17 (22), 14674-14684.

[41] Sum, T. C.; Mathews, N.; Xing, G. C.; Lim, S. S.; Chong, W. K.; Giovanni, D.; Dewi, H. A., Acc. Chem. Res. 2016, 49 (2), 294-302.

[42] Manser, J. S.; Kamat, P. V., Nat. Photon. 2014, 8 (9), 737-743.

[43] Flender, O.; Klein, J. R.; Lenzer, T.; Oum, K., Phys. Chem. Chem. Phys. 2015, 17 (29), 1923819246.

[44] Hu, L. L.; Yang, Z. Y.; Mandelis, A.; Melnikov, A.; Lan, X. Z.; Walters, G.; Hoogland, S.; Sargent, E. H., J. Phys. Chem. C 2016, 120 (26), 14416-14427.

[45] de Quilettes, D. W.; Vorpahl, S. M.; Stranks, S. D.; Nagaoka, H.; Eperon, G. E.; Ziffer, M. E.; Snaith, H. J.; Ginger, D. S., Science 2015, 348 (6235), 683-686.

[46] Kang, B.; Biswas, K., Phys. Chem. Chem. Phys. 2017, 19 (40), 27184-27190.

[47] Christians, J. A.; Miranda Herrera, P. A.; Kamat, P. V., J. Am. Chem. Soc. 2015, 137 (4), 15301538.

[48] Piatkowski, P.; Cohen, B.; Kazim, S.; Ahmad, S.; Douhal, A., Phys. Chem. Chem. Phys. 2016, 18 (39), 27090-27101.

[49] Guo, Z.; Manser, J. S.; Wan, Y.; Kamat, P. V.; Huang, L., Nat. Comm. 2015, 6.

[50] Christians, J. A.; Manser, J. S.; Kamat, P. V., J. Phys. Chem. Lett. 2015, 6 (11), 2086-2095.

[51] Johnston, M. B.; Herz, L. M., Acc. Chem. Res. 2016, 49 (1), 146-154.

[52] Herz, L. M., Annu. Rev. Phys. Chem. 2016, 67 (1), 65-89.

[53] Huang, J.; Yuan, Y.; Shao, Y.; Yan, Y., Nat. Rev. Mater. 2017, 2, 17042.

[54] Yang, Y.; Ostrowski, D. P.; France, R. M.; Zhu, K.; van de Lagemaat, J.; Luther, J. M.; Beard, M. C., Nat. Photon. 2016, 10 (1), 53-59.

[55] Price, M. B.; Butkus, J.; Jellicoe, T. C.; Sadhanala, A.; Briane, A.; Halpert, J. E.; Broch, K.; Hodgkiss, J. M.; Friend, R. H.; Deschler, F., Nat. Comm. 2015, 6, 8420.

[56] Sarritzu, V.; Sestu, N.; Marongiu, D.; Chang, X.; Wang, Q.; Loi, M. A.; Quochi, F.; Saba, M.; Mura, A.; Bongiovanni, G., Adv. Opt. Mater. 2017, 1700839.

[57] Cho, H.; Jeong, S.-H.; Park, M.-H.; Kim, Y.-H.; Wolf, C.; Lee, C.-L.; Heo, J. H.; Sadhanala, A.; Myoung, N.; Yoo, S.; Im, S. H.; Friend, R. H.; Lee, T.-W., Science 2015, 350 (6265), 1222-1225.

[58] Wheeler, D. A.; Fitzmorris, B. C.; Zhao, H.; Ma, D.; Zhang, J., Sci. China Chem. 2011, 54 (12), 2009-2015. 
[59] Stranks, S. D.; Burlakov, V. M.; Leijtens, T.; Ball, J. M.; Goriely, A.; Snaith, H. J., Phys. Rev. Applied 2014, 2 (3).

[60] Hutter, E. M.; Hofman, J.-J.; Petrus, M. L.; Moes, M.; Abellón, R. D.; Docampo, P.; Savenije, T. J., Adv. Energy Mater. 2017, 7 (13), 1602349-n/a.

[61] Hutter, E. M.; Eperon, G. E.; Stranks, S. D.; Savenije, T. J., J. Phys. Chem. Lett. 2015, 6 (15), 3082-3090.

[62] Einstein, A., Ann. Phys. 1905, 322 (8), 549-560.

[63] Lipparini, E., Modern Many-particle Physics: Atomic Gases, Quantum Dots and Quantum Fluids. World Scientific Publishing Co.: Singapore, 2003.

[64] Yamada, Y.; Nakamura, T.; Endo, M.; Wakamiya, A.; Kanemitsu, Y., J. Am. Chem. Soc. 2014, 136 (33), 11610-11613.

[65] Ponseca, C. S., Jr.; Hutter, E. M.; Piatkowski, P.; Cohen, B.; Pascher, T.; Douhal, A.; Yartsev, A.; Sundstrom, V.; Savenije, T. J., J. Am. Chem. Soc. 2015, 137 (51), 16043-16048.

[66] Ponseca, C. S., Jr.; Savenije, T. J.; Abdellah, M.; Zheng, K.; Yartsev, A.; Pascher, T.; Harlang, T.; Chabera, P.; Pullerits, T.; Stepanov, A.; Wolf, J.-P.; Sundstrom, V., J. Am. Chem. Soc. 2014, 136 (14), 5189-5192.

[67] Wehrenfennig, C.; Eperon, G. E.; Johnston, M. B.; Snaith, H. J.; Herz, L. M., Adv. Mater. 2014, $26(10), 1584-1589$.

[68] Wang, H.; Whittaker-Brooks, L.; Fleming, G. R., J. Phys. Chem. C 2015, 119 (34), 1959019595.

[69] Li, Y.; Yan, W.; Li, Y.; Wang, S.; Wang, W.; Bian, Z.; Xiao, L.; Gong, Q., Sci. Rep. 2015, 5, 14485.

[70] Stranks, S. D.; Eperon, G. E.; Grancini, G.; Menelaou, C.; Alcocer, M. J. P.; Leijtens, T.; Herz, L. M.; Petrozza, A.; Snaith, H. J., Science 2013, 342 (6156), 341-344. 

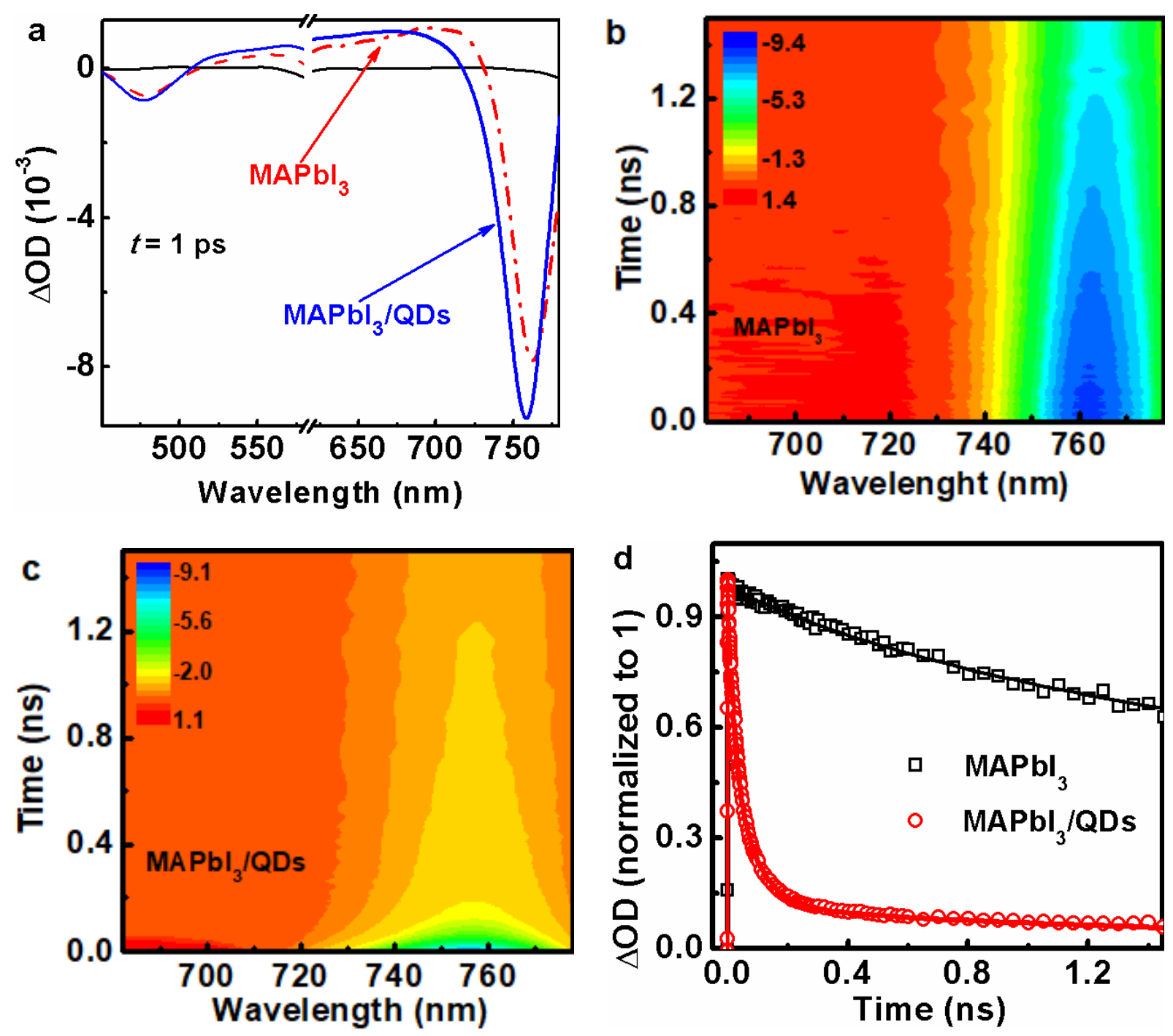

Figure 1. (a) Transient absorption spectra of $\mathrm{MAPbI}_{3}$ (red dashed dotted line) and $\mathrm{MAPbI}_{3} / \mathrm{QDs}$ (blue solid line, $6.3 \mathrm{wt} \%$ ) films at $1 \mathrm{ps}$ pump-probe delay. Two-dimensional pseudo-color $\Delta \mathrm{mOD}$ map of (b) $\mathrm{MAPbI}_{3}$ and (c) $\mathrm{MAPbI}_{3} / \mathrm{QDs}$ films $(6.3 \mathrm{wt} \%$ ) as a function of both observation wavelengths and pump-probe delay time. (d) Normalized transient absorption decays of $\mathrm{MAPbI}_{3}$ and $\mathrm{MAPbI}_{3} / \mathrm{QDs}$ observed at $760 \mathrm{~nm}$. Data were obtained upon excitation at $600 \mathrm{~nm}$. Used fluence of the absorbed photons was $8.2 \times 10^{12} \mathrm{ph} / \mathrm{cm}^{2}$. The solid lines in (d) are from the best fits using the kinetic models described in the text. 

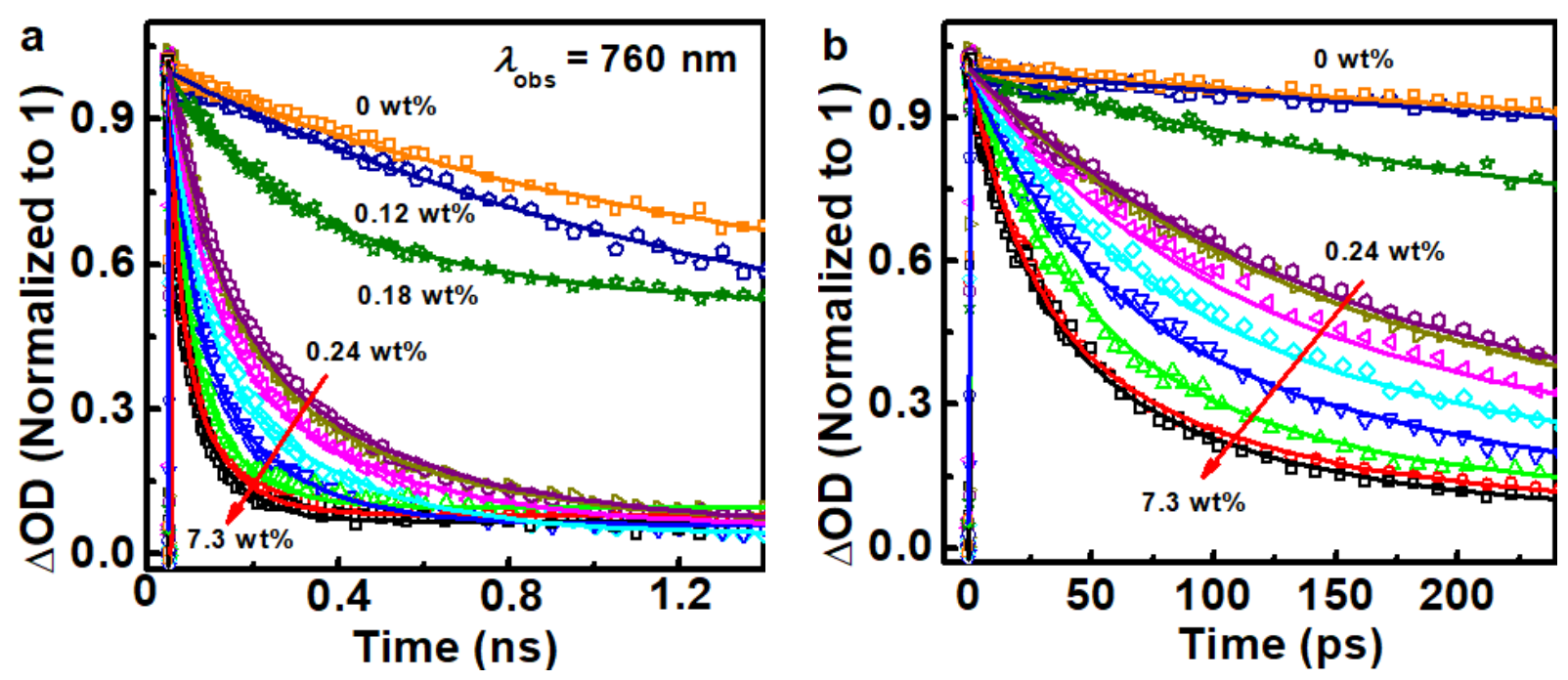

Figure 2. (a) Normalized transient absorption decays of $\mathrm{MAPbI}_{3} / \mathrm{QDs}$ thin polycrystalline films containing QDs of: 0, 0.12, 0.18, 0.24, 0.30, 0.59, 1.2, 2.6, 4.6, 6.3 and 7.3 wt\% (mass percentage). Data were observed at $760 \mathrm{~nm}$, upon excitation at $600 \mathrm{~nm}$, and using fluence of the absorbed photons $8.2 \times 10^{12} \mathrm{ph} / \mathrm{cm}^{2}$. (b) is a zoom of (a) to show the decays up to $250 \mathrm{ps}$. Solid lines are from the best fits using the kinetic model described in the text. 
A

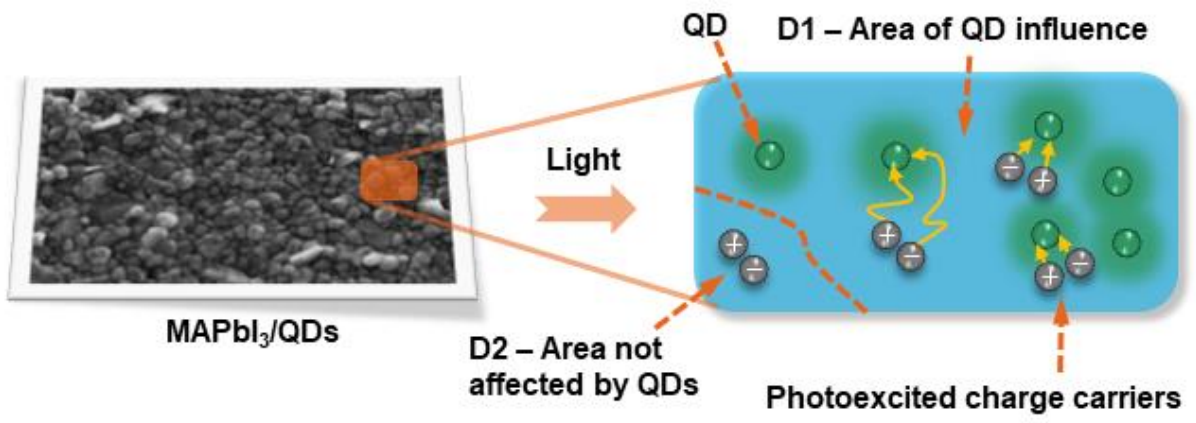

B

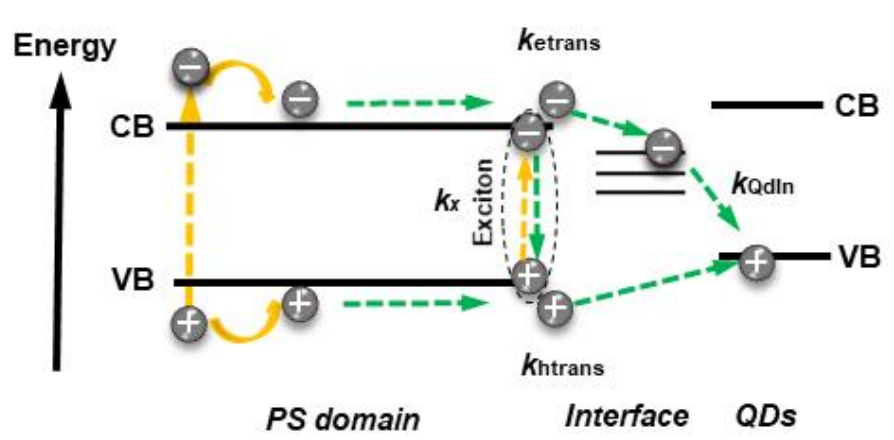

C

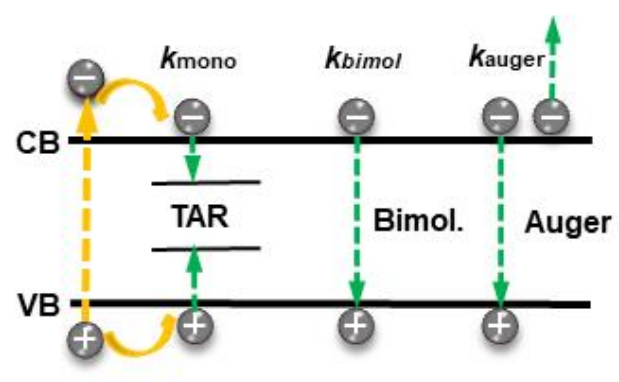

PS domain

Figure 3. (a) $\mathrm{SEM}$ of $\mathrm{MAPbI}_{3} / \mathrm{QDs}$ and the cartoon showing the areas of QDs influence (D1) and without their influence (D2) upon excitation over the band gap of perovskite. (b) Energy diagram showing the dynamics of photoexcited charge carriers in $\mathrm{MAPbI}_{3} / \mathrm{QDs}$ film in $\mathrm{D} 1$ area and (c) D2 area upon excitation over the band gap. For clarity, (b) only shows the processes involving the influence of QDs, while those in (c) representing the classical events in neat perovskite. $k_{\text {etrans }}$ and $k_{\text {htrans }}$ characterize the effective transfer processes of charge carriers from perovskite to the interface or/and QDs. $k_{\mathrm{x}}$ is the exciton recombination rate constant. $k_{Q d I n}$ is the recombination rate constant between trapped electrons and holes in QDs. The positions of the energy levels are taken from references [23, 37]. See text for details. 

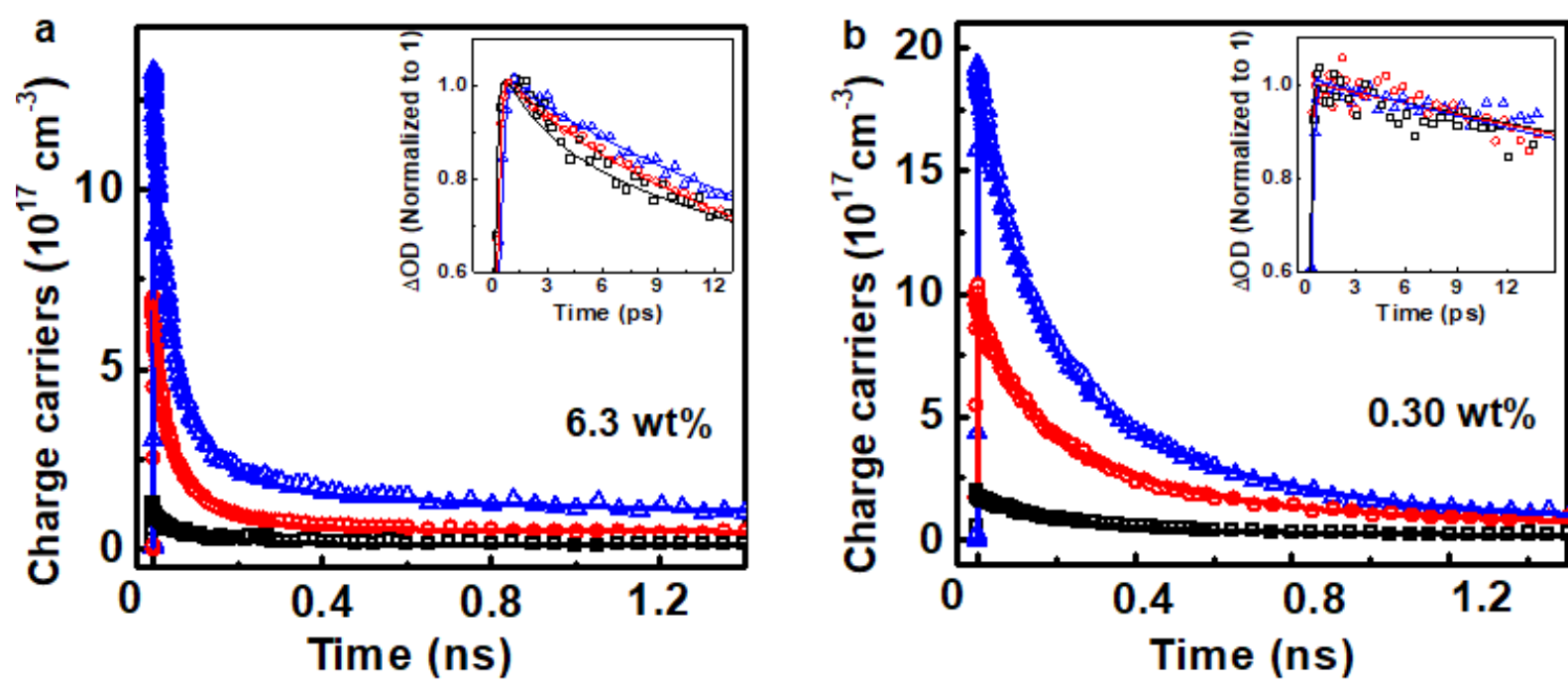

Figure 4. Decays of transient absorption signal converted to charge carrier concentration of $\mathrm{MAPbI}_{3} / \mathrm{QDs}$ thin films containing (a) $6.3 \mathrm{wt} \%$ and (b) $0.30 \mathrm{wt} \%$ of QDs. Data were observed at 760 , upon excitation at $600 \mathrm{~nm}$. Used fluences of the absorbed photons were: $1.5 \times 10^{12}$ (black squares), $8.2 \times 10^{12}$ (red circles) and $16 \times 10^{12}$ (blue triangles) $\mathrm{ph} / \mathrm{cm}^{2}$. The insets are the normalized zooms of (a) and (b) to show the short-time behaviour. The solid lines are from the best fit using the kinetic model described in the text. 

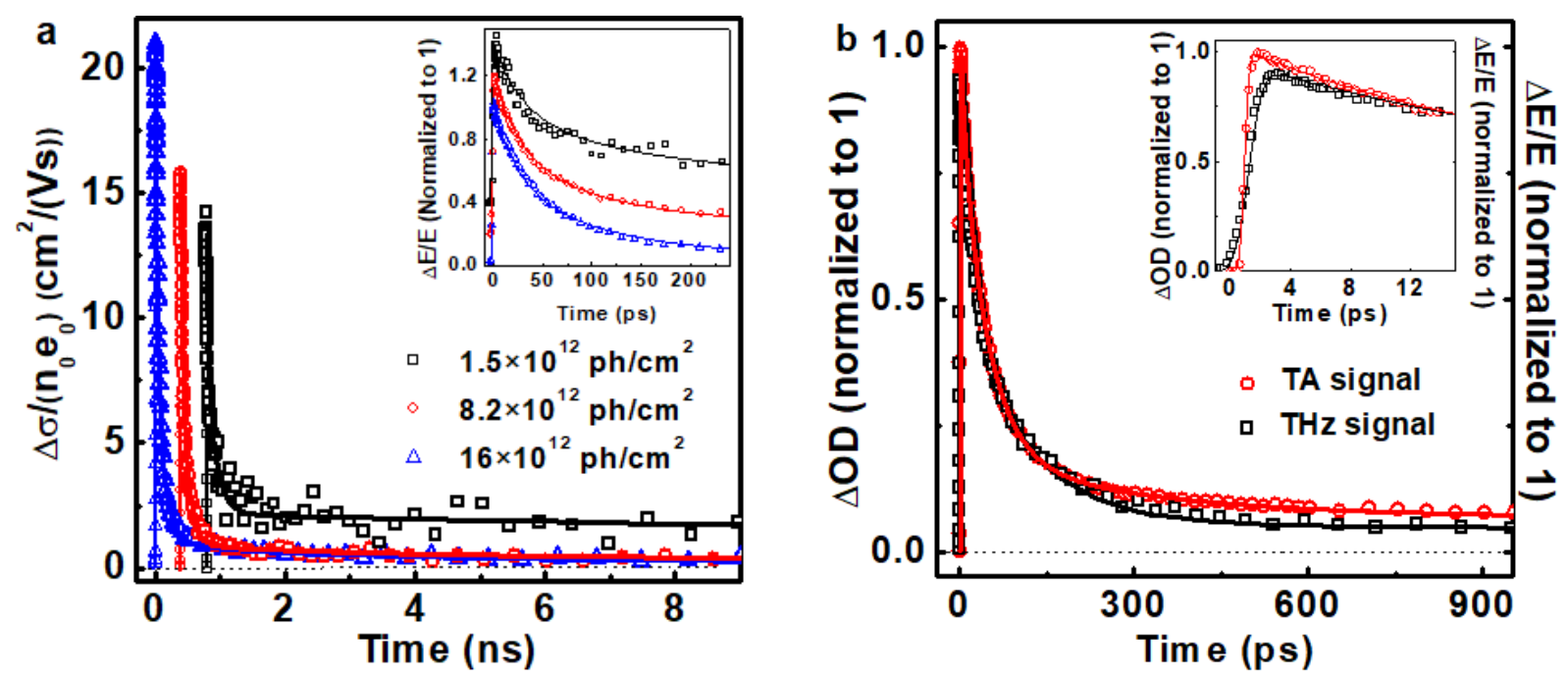

Figure 5. (a) Photoconductivity decays of $\mathrm{MAPbI}_{3} / \mathrm{QDs}$ film $(6.3 \mathrm{wt} \%)$ excited at $600 \mathrm{~nm}$ and using fluences of the absorbed photons: $1.5 \times 10^{12}$ (black squares), $8.2 \times 10^{12}$ (red circles) and $16 \times 10^{12} \mathrm{ph} / \mathrm{cm}^{2}$ (blue triangles). (b) Normalized photoconductivity and transient absorption decays of $\mathrm{MAPbI}_{3} / \mathrm{QDs}$ film (6.3 $\mathrm{wt} \%$ ), excited at $600 \mathrm{~nm}$ and using a fluence of the absorbed photons of $8.2 \times 10^{12} \mathrm{ph} / \mathrm{cm}^{2}$. The insets are zooms to show the short-time behaviour. The TA signal was observed at $760 \mathrm{~nm}$. The solid lines are from the best fits using the kinetic model described in the text. 
Transient absorption, $\lambda_{\text {pump }}=600 \mathrm{~nm}, \lambda_{\text {obs }}=760 \mathrm{~nm}$

\begin{tabular}{|c|c|c|c|c|}
\hline $\begin{array}{c}C_{Q D s} \\
(w t \%)\end{array}$ & $\boldsymbol{k}_{\text {htrans }}\left(10^{10} \mathrm{~s}^{-1}\right)$ & $\boldsymbol{k}_{\text {etrans }}\left(10^{10} \mathrm{~s}^{-1}\right)$ & $P_{D 1}(\%)$ & $P_{D 2}(\%)$ \\
\hline 7.3 & 4.6 & 1.2 & 92 & 8 \\
\hline 6.3 & 4.3 & 1.04 & 90 & 10 \\
\hline 4.6 & 3.0 & 0.87 & 90 & 10 \\
\hline 2.6 & 2.1 & 0.54 & 89 & 11 \\
\hline 1.2 & 1.5 & 0.37 & 89 & 11 \\
\hline 0.59 & 1.2 & 0.29 & 89 & 11 \\
\hline 0.30 & 0.95 & 0.24 & 88 & 12 \\
\hline 0.24 & 0.81 & 0.22 & 88 & 12 \\
\hline 0.18 & 0.39 & 0.002 & 85 & 15 \\
\hline 0.12 & 0.13 & 0.002 & 5 & 95 \\
\hline $\mathbf{0}$ & -- & -- & -- & 100 \\
\hline
\end{tabular}

Table 1. Values of the effective transfer rate constants, $k_{\text {htranst }}$ and $k_{\text {etrans, }}$ and D1 and D2 population fractions $\left(P_{\mathrm{D} 1}, P_{\mathrm{D} 2}\right)$ obtained using the kinetic model described in the text to fit the transient absorption decays of $\mathrm{MAPbI}_{3} / \mathrm{QDs}$ film, containing the indicated concentration of QDs (Figure 2). TA data were observed at 760, upon excitation at $600 \mathrm{~nm}$, and using fluence of the absorbed photons $8.2 \times 10^{12} \mathrm{ph} / \mathrm{cm}^{2}$. The population fractions of excitons $\left(P_{\mathrm{x}}\right)$ in $\mathrm{D}_{1}$ in samples containing $C_{Q D s}$ of 7.3, 6.3 and $4.6 \mathrm{wt} \%$ are 7,6 and $4 \%$, respectively. For these samples, the recombination rate constants of the excitons, $k_{\mathrm{x}}$, are $\sim 3.5 \times 10^{11} \mathrm{~s}^{-1}$. For $C_{Q D s}$ lower than $4.6 \mathrm{wt} \%$ the $P_{\mathrm{x}}=0$. 